\title{
Concordance-based Material as a Form-focused Solution to Constituent Misordering
}

\author{
Kunlaphak Kongsuwannakul, Suranaree University of Technology, Nakhon Ratchasima, Thailand
}

\begin{abstract}
This paper investigates the effectiveness of concordance-based material for an EFL problem-misordering in expressions of measurement. A specifically designed pre-and posttest is developed for testing Thai students' ability to use the expression. The sample comprises four groups of university students in their first and second years (two groups each). One first year group and one sophomore group are experimental ones, and the other two control groups. In the pretest and the posttest, they are all instructed to arrange chunks (i.e., constituents) into complete sentences. The experimental groups are exposed to a concordance-based, self-study material before taking the posttest. An ANOVA shows that they arrange the constituents in the posttest significantly more accurately at $p<=.001$ than do the control groups. The material is argued for raising their awareness of the distinct ordering. Hence, concordance-based material could be applied to other form-focused problems in EFL.
\end{abstract}

Keywords: Experiment, Concordance, Material Design, Ordering, Effectiveness, Testing

\section{INTRODUCTION}

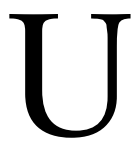

se of corpora in applied linguistics and language teaching seems to have been proliferating ever since computer technology allowed efficient processing of considerable amounts of text in a feasible manner. Its approximate origin, from my literature review, can be traced back to the late 1870s when corpus linguistics came in the form of a compilation of parents' diaries to study locutions in child speech, a study in language acquisition (Bartsch ca. 2006). According to Bartsch (ca. 2006), Thorndike's (1921) book The Teacher's Wordbook is among those pioneering corpus-based publications in the realm of language pedagogy.

Concordancing, a major approach to gaining insights into language features in a corpus, has been being utilized quite extensively in English language teaching (ELT) and related areas. For learners, this use ranges from understanding meaning of new words (e.g., those discussed in Thurstun and Candlin 1998) to discovering the functions of lexical bundles (e.g., Byrd and Coxhead 2010), from interpreting meaning of unknown idioms (e.g., Aston 2002) to noticing certain grammatical patterns (e.g., English verb inflections in Ching and Wong 1994).

Notwithstanding the extensive corpus-based use, there seems to be, however, little interest in ELT in exploring the feasibility of concordance application to differing constituent orderings between English and a native language. For instance, Bryd and Coxhead $(2010,31)$ make a review that "[c]urrently, much of the reported research [on use of formulaic patterns] focuses on lexical bundles." This view accords well with Flowerdew's $(2009,399)$ note that lexical bundles and collocations are part of "phraseological routine" of corpus-based applications in pedagogy. That is to say, many of the applications are limited to vocabulary and meaningful, native-like use of phrases. This common practice in the field could be reckoned as somehow neglecting the long-known potential problem of ordering to EFL learners (a structural difficulty discussed in, for example, Odlin's (1989) classic book Language Transfer and Byrd (2008)).

The International Journal of Pedagogy and Curriculum

Volume 19, 2013, http://thelearner.com/, ISSN: 2327-7963

A C OM MO N

(C) Common Ground, Kunlaphak Kongsuwannakul, All Rights Reserved, Permissions:

$G R O U N D$

cg-support@commongroundpublishing.com 
Likewise, it neglects the fact that colligational queries-certainly including those on constituent ordering - can also be examined through corpus-based approaches.

Considering these circumstances, this paper aims to present findings from an application of concordancing to coping with a learning difficulty posed by the distinct order of an English expression (i.e., expression of measurement, as will be justified in the next section) from that in a native language (here the Thai language). This, at the very least, explores further usefulness of concordancing for EFL students and, plausibly, encourages a similar application of concordance-based material for students of other first language backgrounds. The paper, in this way, is trying to answer a call for more research on corpus-based applications to pedagogic use, an area in corpus linguistics that has a lot more room for further development and exploration (Flowerdew 2009).

\section{Expressions of Measurement in Previous Research}

In the English language, there are hundreds, if not thousands, of expressions available for learners. Expressions of measurement are part of those. However, the measurement expressions are, from my literature review, not really much studied academically, in spite of the fact that somehow they, in Hasegawa et al.'s $(2010,2)$ view, can at least help us be "prepared for the needs of modern industrial society."

The first study on the measurement expressions found in literature is Hasegawa et al. (2010). They study the expressions in an encoding approach (or, in their term, an onomasiological approach) under the framework of Sign-Based Construction Grammar. They divide the expressions into three categories (p. 2):

1. Measurement (e.g., the window is a meter wide),

2. Comparison (e.g., this window is wider than that one), and

3. Measured difference (e.g., this window is 4 centimeters wider than that one).

They use the framework and find that the Japanese and English expressions are not completely matched in semantic terms.

The other one is my previous, preliminary study, Kongsuwannakul (2009). Kongsuwannakul (2009) presents a fundamentally contrastive analysis of the English and Thai expressions of measurement and proves that there is really a hardship for Thai students to master this structure in English, plausibly owing to its distinction from that in their mother tongue. Note that in Kongsuwannakul (2009), only Hasegawa et al.'s (2010) first category of measurement expressions is dealt with (i.e., the window is a meter wide). To set the scene for the experiment on effectiveness of the concordance-based material conducted and reported in this paper, I will first discuss Kongsuwannakul (2009) to some extent below.

\section{Distinct Orders of the Expression}

Below is a couple of contrasting pairs $((1 \mathrm{a}-\mathrm{b})$ and $(2 \mathrm{a}-\mathrm{b}))$ for the expression (adapted, Kongsuwannakul 2009). For convenience of a general audience, the Thai counterparts follow Thailand Royal Institute's (1999) transcription guidelines. 


\section{(1) (a) (English) \\ (b) (Thai) \\ (2) (a) (English) \\ (b) (Thai)}

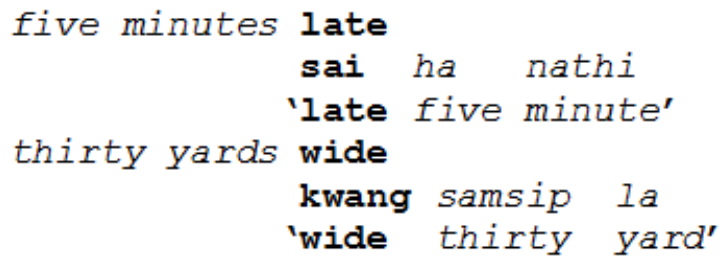

From (1a) and (2a) above, English puts quantifier phrases before their heads whereas, from (1b) and (2b), the Thai language puts quantifier phrases after their heads. Consequently, we can justifiably claim that English and Thai expressions of measurement are markedly different in terms of constituent ordering.

\section{Empirical Difficulty of the Expression for Thai Students}

From the distinct nature of the expression in the two languages, Kongsuwannakul (2009) speculates that these completely different constituent orders (cf. Section Distinct orders of the expression above) will plausibly cause trouble to Thai students when using the expression in English. To prove this, she develops a 24-item multiple-choice test to assess how the sampled students would arrange the constituents of each sentence containing the expression. The test has been specifically designed so as to minimize the probability of guessing a correct answer. Each test item has more than four possibilities to arrange the constituent boxes. Test takers will need to approach the test more actively when compared with normal multiple-choice tests. No filler items are used since the test is originally aimed at being unitary in terms of trait measured. The first two items of the test are provided below in Figure 1 (see also Appendix A for the sentences of all the 24 test items). All the test items are of similar format.

1.

$$
\text { around } 12 \text { inches }
$$
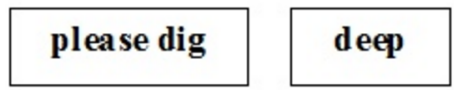

\section{a hole}
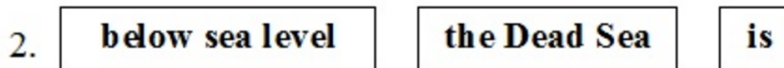

\section{0 meters}

Figure 1: Two Test Items on the Measurement Expression (Kongsuwannakul 2009, 299)

The quality of the test has been verified in terms of a) content validity through the index of item objective congruency (IOC), and b) reliability through the Cronbach's alpha coefficient method. There are four groups of English major students-156 students altogether-participating in the testing. Two of the four groups are at the first year undergraduate level, and the other two the second year. They were all studying a similar English major course in four different sections (i.e., groups/classes) during the same semester at a university in Thailand. Their enrollment in the four different sections is on the basis of their student ID numbers (i.e., student 
identification numbers), not the arrangement of their grade points or proficiency. Thus, their English proficiency is mixed. Their grade point averages are also generally examined to ensure this.

In the testing paper, they are requested to arrange the boxes of each item into correct order. Their answers are then marked either ' 1 ' (one) or ' 0 ' (zero) for correct or incorrect ordering respectively. With the Levene's test statistic, it is found that the mean scores of all of these four groups are homogeneous with equal variances assumed. Their performances in the test, by means of an analysis of variance (ANOVA), are not significantly varied across groups. In conclusion, the mean scores of their performance as to arranging the sentences containing measurement expressions are statistically equally low. (Note again that this testing acts as the pretest in the present paper (cf. Kongsuwannakul 2009 for details of the construction of the test).)

None of their average scores reaches even half of the maximum score (i.e., all lower than 12 out of 24). Two of the groups-which function as control groups in this current experiment-have also been selected for a retesting interpretation (cf. Section Effectiveness of the concordance-based material). This is viewed as a way to check the reliability of the testing paper (Kanjanawasee 2005). The retest interpretation reveals and confirms that the low scores from the misordering are still consistent throughout. The error seems to be linguistically inherent. Consequently, her hypothesis proves true, and Kongsuwannakul (2009) therefore claims that the earlier presumed ordering difficulty truly exists. The misordering, in my view, is very plausibly because of the students' unawareness of the cross-linguistic distinction (cf. language examples (1) and (2) above). The misordering existing in both first and second year students substantiates her claim in terms of negative transfer in that the error is systematic and cannot be eradicated merely by higher exposure to the English language through time (Kongsuwannakul 2009). The following (Figure 2) are four real answers taken as examples from each group, together with their possible Thai translations to support the assertion:

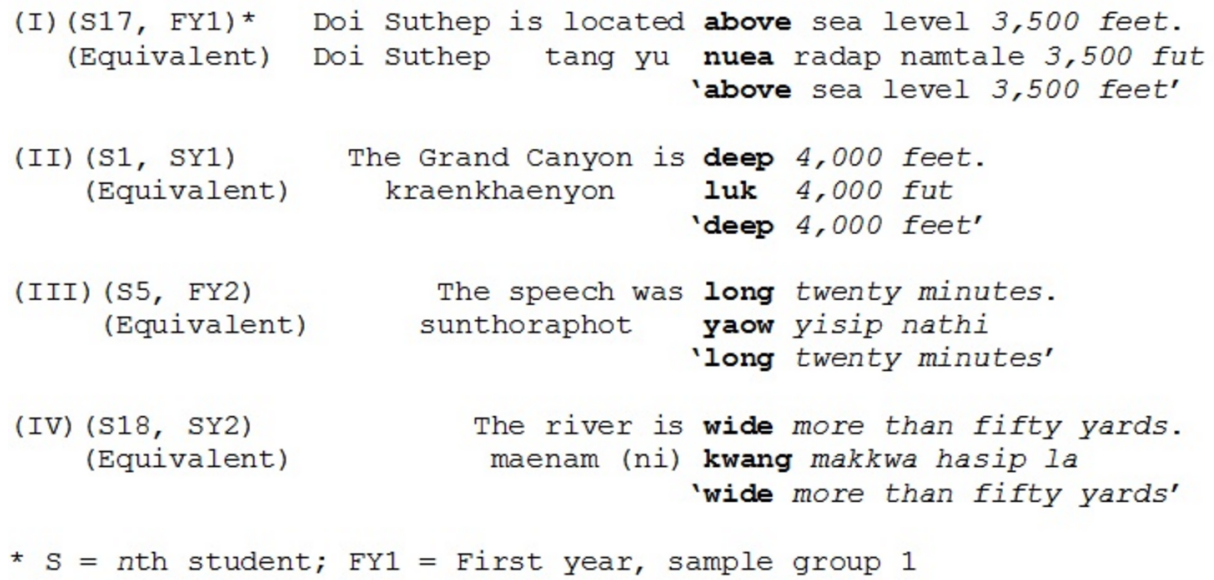

Figure 2: Concordance of students' selected answers with their Thai equivalents (adapted, Kongsuwannakul 2009, 303)

From (I)-(IV) in Figure 2 above, it is clear that the participating Thai university students tend to negatively transfer the ordering system already existing in their mother tongue into their use of the equivalent expression in English. As a generalization, this measurement expression in English is potentially problematic to Thai students in the main on account of its different constituent ordering from that in their Thai mother tongue, thereby easily inducing misordering of the expression. 


\section{Concordance-based Material as a Form-focused Solution}

Given the true existence of the misordering problem under discussion here, I find it worthwhile to seek an effective solution to it in the current paper. Concordancing, for various reasons, seems a promising choice for the purpose.

\section{What Lies Beneath Concordancing?}

Concordancing, first of all, has its own drawbacks and advantages just as any other approach in ELT does, and linguists still have a lot more to do before corpus linguistics-its 'mother' field of study-becomes a well-established discipline with a hard-and-fast body of comprehensive knowledge. Still, in spite of the premise that it is a growing discipline in applied linguistics, some current perspectives on it are worth considering here. Flowerdew (2009) critically evaluates several strengths and weaknesses of corpus linguistics to some extent, especially with respect to the widely held, seeming myths perpetuated about the application of corpus linguistics to pedagogy. Among them, those related to the argument for corpus-based application here are a) exclusively bottom-up processing, and b) nontransferability of insights.

With regard to the myth of bottom-up text processing, Flowerdew $(2009,396-402)$ reviews and insists by means of a good number of studies that there is a current trend of corpus-based applications to discourse-based pedagogic use that are a combination between top-down and bottom-up processing of text. She espouses the notion that both ways of text processing are complementary to each other and thus, when integrating the two, an exploration of a corpus or a corpus-based query can anyway reveal an inherent nature of a discourse. In my view, this idea is particularly true when we consider the top-down processing and the bottom-up processing as not being mutually exclusive, whereby there appear, just as Flowerdew $(2009,395-6)$ herself holds, simply different starting points for a linguistic investigation.

Nontransferability of insights from corpus-based investigations, moreover, is somewhat fallacious when one considers applying them to pedagogic settings. Some say corpus data are merely samples of language, thus deprived of context necessary for students to process and interpret the text properly and for this reason not enabling the students to transfer what they learn through corpus-based queries (Flowerdew 2009). However, to this remark Flowerdew $(2009,403-5)$ rightly argues that this challenge seems to depend to a large extent on what is to be transferred, and on this account, certain forms of pedagogic mediation (e.g., peer discussion and didactic writing hints) can be utilized so as to point out the pragmatic appropriacy and discipline-related variation to the students. That is to say, with appropriate mediation of corpusbased applications used, students can learn from corpora and transfer their insights pragmatically. She also adds that the 'co-textual environment' (i.e., the surrounding text of a key word in the concordance lines) can also provide some clues as to context since it is actually part of the 'extended unit of meaning'.

After tackling a few myths of pedagogic corpus-based application, certain strengths should also be mentioned insofar as the experimentation of this paper is justified. The key point in favor of the effort to experiment a concordance-based material is data-driven learning (DDL), the term first created by Tim Johns in the 1980s (Kilgarriff 2009, 4). Just as the term itself says, students will learn on the basis of the language data given to them, and it is the language data that instigate their learning. The success of learning lies in the paradigmatic arrangement of multiple language samples presented with the key word in the center of the lines, also known as Key Word In Context (KWIC) (see, for example, Kilgarriff 2009, or cf. Appendix B for an example of the paradigmatic arrangement). When shown in a concordance, "the patterns in which ... [a] given word or phrase is typically used" (Flowerdew 1993, 87) is thus drawn to the learner's attention, thereby assisting the discovery of the grammatical rules attached to the word (ibid.). In other words, grammatical rules can be derived from their recurring patterning when their concordance lines are arranged vertically with the key word centered. DDL points 
out what is needed and pertinent to the learner. It can as a consequence induce acquisition and long retention (e.g., Kilgarriff 2009).

Flowerdew $(1993,94)$ also suggests that error analysis and correction be a 'guided' use of a concordancer insofar as the learners can spot the difference between their own language production and the authentic language usage. Given that the English expression of measurement is problematic to Thai students in this current paper (cf. Section Empirical difficulty of the expression for Thai students above) and is formal in nature (as opposed to functional or semantic ones), it can be conceived that the strengths of concordancing in terms of pattern discovery and language self-correction will enable the research sample—or even EFL students in general-to notice the different patterning of the expression.

Note also that the factor of noticing and paying attention is truly crucial to the probable success of concordance-based material and thus the selection of this kind of material in the present experiment (and also to the design of the concordance-based material in this paper, which will be discussed in Section Design of concordance-based self-study material below). This psychological factor is reckoned as consciousness in action and can convert unrecognized language features into effective learning (Schmidt 1990; see also Kilgarriff 2009, 3-4). It is also known as 'cross-language awareness' in action (Laufer and Girsai 2008, 710). When students are forced to notice the salient feature of a language item, e.g., by means of 'cross-linguistic' instruction, effective learning occurs (ibid.). Also just as Kilgarriff $(2009,4)$ reviews, language discoveries through DDL "are very likely to be remembered." Perhaps on this account, it is widely agreed that learning through DDL discovery can motivate learners to explore more (e.g., Tan 2002), encourage long learning retention (e.g., Kilgarriff 2009; Supatranont 2005) and at the same time train them to be sensitive to various linguistic features.

In short, concordancing is justifiably robust for applications in the area of pedagogy since it - as effective methodology for tackling linguistic enquiries (Flowerdew 2009)—can render DDL, and through mediation, pedagogic applications can still be meaningful for learning. Facts about language learned through DDL will likely be retained over time (a feature that will be proved in the posttesting of this present study).

\section{Concordance-based Material for Form-focused Instruction}

Providing that corpus-based applications to pedagogic use are arguably beneficial and can plausibly enrich the mastery of the measurement expression, and there is still a lot to be done in the area, my effort to address the misordering problem takes up concordancing. To put it specifically, concordancing, as summarized above, is a pertinent answer to the problem in hand.

\section{Is Form-focused Instruction Worth Tackling?}

Since this paper discusses the effectiveness of concordance-based material for a structural problem, a question may be raised in such a way as 'Is the problem worth tackling, after all?' That is, even if the expression is really problematic (cf. Section Empirical difficulty of the expression for Thai students), why should we care if, after all, the students can already communicate in English and get their meaning across?

In order to address the issue, a couple of constructs in ELT are worth discussing here. First of all, it should be reminded that the communicative language teaching approach (CLT) is not everything in ELT; there are plenty of 'successful' English learners around the globe having not undergone CLT or just also utilized other approaches (Bax 2003). Although CLT has been proposed for so long and widely practiced in the area of ELT, it has been lately criticized, for one thing, because it (or actually some practitioners) seems to rule out other equally valid approaches in teaching English to speakers of other languages (TESOL). According to Bax (2003, 281), the common practice of CLT nowadays is creating such inflexible attitudes as "[n]o 
other factors count in language learning" and "CLT is the complete answer." However, just as Nunan (2001, Section 2, para. 1) puts it concerning the trends in L2 curricula, the quest "for the one best method [...] would seem to be well and truly dead." Similarly, Zhang (2008, 102) encourages that "an EFL teacher should endeavor to use various teaching methods or measures to meet EFL learners' diverse needs, including the use of corpora." Therefore, we could put it simply here that any method would count as far as it is justified and effective, corpus-based ones certainly included.

Apart from there being no single, best instructing method in ELT, previous studies also reveal that an entire focus on communicative skills does not yield encouraging results. Poole (2005, 48 ) shows that the 'purely communicative instruction' alone (which equals, in his review, focus on meaning instruction) cannot enable students to as well acquire difficult language forms as can focus on form instruction. By way of multiple examples in ELT literature, Poole (2005, 49 ) illustrates that focus on form instruction provides students with more remarkable accuracy, better performance, and more careful attention when they deal with, for example, verb usage, tense usage, and adjectival participles, as opposed to those with focus on meaning instruction. By contrast, this purely communicative instruction, theoretically, does not seem to appreciate 'direct grammar teaching' at all (Poole 2005, 48).

In passing, note that focus on form instruction as used by Poole $(2005,48-9)$ here must not be confused with his term of 'focus on forms' instruction, in which grammatical rules are planned in advance and explicitly explained to students. The latter, as research shows, seems not to promote retention of what the students have learned when compared with contextualized learning (Poole 2005, 49).

Another point to address here is the definition of the term form-focused used in this current paper. Poole's (2005) use of the term 'focus on form' seems to aim chiefly for language classroom instruction in which occasional attention is paid to forms primarily amidst other instructing modes. However, since a) the term 'form-focused' has recently been reviewed as inclusive of both 'focus on form' and 'focus on forms' (Laufer and Girsai 2008, 695), and b) the concordance-based material reported in this paper can be viewed as a mix of the two, I find it most appropriate to propose this contextualized material (cf. Appendix B) as a form-focused solution in accordance with Laufer and Girsai's (2008) classification, rather than a focus on form one.

Returning to the warranted quest for an effective method outside of the realm of a pure CLT, perspectives from literature also support the call for form-focused instruction itself. For example, Nation $(2003,1)$ states that in a 'well-balanced' L2 instruction, an approximately equal weight should also be given, out of his four emphasized aspects, to "language focused learning-learning through deliberate attention to language features." Moreover, Ellis $(2005,11)$ reiterates the idea by proposing a principle of instructed language learning that "[i]nstruction needs to ensure that learners also focus on form" [italics mine], indicating that ELT cannot put emphasis merely on communicative meaning. On this account, the aim for developing form-focused material here is fully warranted.

\section{Design of Concordance-based Self-study Material}

So far, a) the need and justification for attending to the English expression of measurement problematic to Thai students (cf. Section Expressions of Measurement in Previous Research above) and b) the potential of concordance-based material in providing a contextualized source of information about a linguistic enquiry (cf. Section What lies beneath concordancing?) have been covered. This section will then justify and describe the construction of the concordancebased self-study material as a feasible form-focused solution to misordering in expressions of measurement. 


\section{Why Concordance-based Self-study Material?}

In literature on pedagogic use of corpus-based material, there have been quite a large number of cases where such material is introduced to classroom settings directly and electronically (See, e.g., Flowerdew 2009; Kilgarriff 2009). For instance, Aston (2002) takes to the class an English newspaper article and a laptop computer installed with the British National Corpus (BNC) and lets his non-native students have a hands-on investigation of unknown vocabulary and idioms found in the article right through the corpus. In this fashion, students can more or less take a role of language explorer or traveler (as reviewed by, for example, Flowerdew 2009).

However, considering my own sociocultural contexts where large class size is usually a big challenge for teachers (UNESCO 2006), I find it more controllable to explore the feasibility of constructing a paper-based self-study material, as opposed to exploring a material to be used entirely in class activities or exploring how to apply it fully electronically. This kind of paperbased material should allow a relatively effective control over such research factors as testing time and seating for participants, since I do have several large groups of research participants in the experimentation.

Conversely, were experimentation with an electronic concordance-based resource to take place purposefully on students, the probable results could be radically affected by the students' (in)ability to select appropriate concordances and use electronic tools properly. This is an aspect whose importance has been much underscored in literature and that still needs much research before ways and means and definite insights can be yielded (Flowerdew 2009). Since a corpus is a huge collection of data full of authentic yet assorted and varied examples of how language is exploited in reality, some inexperienced or weak students may need special care, such as peer interaction and group discussion, in order that they can make proper use of what they discover in concordancing (Flowerdew 2009). This scenario seems inconceivable for an experiment like the present one, where all of the sample groups really have mixed English proficiency.

What's more, a greater use with less variation is another factor taken into account. A purely class-based material may entail variation in effectiveness if used in different circumstances since inter-instructor variability is presumably applicable to a large extent. For instance, those who wish to use a specifically class-based material in their own class may probably find a different result-especially in terms of effectiveness-if teaching experience and style have to play a dominant role in implementing the material successfully. On the contrary, if a paper-based selfstudy material is to be introduced later into a classroom setting instead—a case vice versa—such variability should not be really great. Be reminded, nonetheless, that concordancing can also be a "powerful tool for independent [...] learning" (Aston 2002, 142).

All in all, as these two sources of variation (i.e., mixed ability to approach concordances and inter-instructor variability) can have an adverse effect on experimental results in which several factors need controlling, my experiment here employs a paper-based self-study material to assess the effectiveness of concordancing for the constituent misordering problem. As such, the probable influence of different teaching styles and approaches and students' computer literacy on the experimental effectiveness can be minimized. This ELT use of corpus-based material is termed 'indirect', whereby better instructing materials can still be developed (Kilgarriff 2009, $4)$.

\section{How the Concordance-based Material is Created}

When examining the salient features of corpus-based material exploited in earlier research, a design of material in which only the desired feature is highlighted is generally encouraged. For example, Zhang $(2008,112-4)$ exemplifies a concordance-based application of a mini-corpus vis-à-vis the Lancaster Oslo/Bergen corpus (LOB) with the KWIC centered and brightly colored and with its collocate colored differently. Sripicharn (2003) also does a similar thing. He centers and makes boldface the KWIC verbs in his teaching materials, and underlines, e.g., a noun 
phrase object of the first concordance line so as to lead the students' attention to the 'lexical relations' of all the concordance lines. Therefore, the concordance-based material created and reported in this paper takes this practice into account, using boldface and italics for a key adjective or preposition and its quantifier phrase, respectively (see Appendix B).

Note that in Byrd's (2008, para. 12) matrix of difficult-easy English language features to teach and/or to learn, "basic word order in sentences" is categorized in "Easy to Learn and Easy to Teach." So, I infer that constituent ordering in measurement expressions would fall into the same category since it also involves the way to arrange components grammatically. Providing that concordancing is effective at raising awareness of a particular pattern (cf. section What lies beneath concordancing? above), a simple design would do as far as it can point out the correct arrangement of the expression to students. This helps explain why in the current research the present paper-based concordance of boldface KWIC adjectives or prepositions and italicized quantifier phrases used in context should be sufficient for the purpose here.

In a way, this design of the concordance lines (as found in the rectangular box of the material in Appendix B) reflects one underlying notion in concordance-based application-extended unit of meaning (cf. earlier discussion in Section What lies beneath concordancing?; Flowerdew 2009 for further details). Examining the material closely (cf. Appendix B), I find that a key adjective or preposition in the center (i.e., the 'KWIC' position) forms a paradigmatic relationship with the other KWIC adjectives/prepositions. For one reason, they belong to more or less the same vocabulary domain, i.e., measurement. Together with these KWICs being in association with one another, their corresponding quantifier phrases are also establishing syntagmatic relations with their own adjacent constituents, whereby consciousness is aimed to be triggered. The bidirectional bond is thus capable of being a potential tool for self-correction of the problematic constituent ordering (cf. Section What lies beneath concordancing? or Flowerdew 1993). That is, students will go beyond the KWICs themselves, and when casting their attention span, they will very likely see the intended structure of the expression.

To ensure the workability of the material, I also adopt the later-termed 'dynamic paradigm' for corpus-based investigations proposed by Flowerdew $(2009,407)$. In this approach, hints such as clues and prompts are used to mediate the continuum of induction and deduction, thereby reducing the difficulty of inducing a pattern or 'phraseological tendencies' (Flowerdew $2009,407)$. As a result, five more questions are also provided at the end of the concordance so as to function as step-by-step clues and induce students' desired awareness of the distinct ordering of the English expression of measurement. Put simply, they are supposed to put their awareness into action when used as part of the self-study material (see Appendix B for details of the five questions mentioned here).

The sentences in the material are derived with adjustment from those used in the specially designed pre- and posttest (cf. Section Empirical difficulty of the expression for Thai students; Kongsuwannakul 2009, 306-7). The adjustment is that at least one word in each sentence has been changed. For example, 'Christmas is only a month away' (Appendix A) is changed to 'Halloween is only a month away' (Appendix B). The purpose is to curb rote learning of the material's sentences-which might result in less awareness of the distinct feature in the material and less application of the knowledge to the posttest to be performed later. In other words, the minute change to each sentence is made in order that the students in the experimental groups will take more particular notice of the recurring pattern existing in the concordance lines rather than simply finding and reciting answers to their earlier given pretest. The change should make more room for a true application of their acquired knowledge in the posttest.

The items in the material are arranged in alphabetical order of the key adverbs/prepositions and in left sorting (see Appendix B). The left side of the KWIC is, of course, the position of the quantifier. With a view to implementing it as a self-study material, I keep it short (i.e., one page long) but meaningful (i.e., the intended focus emphasized). This should allow its usefulness as 
a tool for independent learning and an inspiration for other similar material designs to a great extent (see also the discussion in Why concordance-based self-study material? above).

However, note that I by no means intend it to replace other well-established ELT approaches, but rather merely complement them in a tangible manner when dealing with similar form-focused challenges. This is to conform to former observations like:

[C]lassroom concordancing should not be regarded as the only means or technique of presenting language data to the learners. Concordance-based materials therefore should be used together with some other teaching resources or materials such as songs or newspapers. (Sripicharn 2003, 222)

\section{Effectiveness of the Concordance-based Material}

From the pretesting (cf. Section Empirical difficulty of the expression for Thai students), it turns out that each level (first or second year) has one higher group. Though not statistically different from one another at all, the mean scores in the pretest can be roughly clustered into a lower pair (FY2 and SY2) and a higher one (FY1 and SY1) (cf. Table 1 below for how their performance can still reflect the clustering in the posttesting). The higher pair is chosen as experimental groups on a learning opportunity basis. That is, the higher cluster has less room to score better; hence, the concordance-based material needs to work so well as to take the groups to a significantly superior level. The scenario is vice versa for the control groups. For instance, two weeks between the pretesting and posttesting may encompass certain contributing factors (or even other extraneous factors) to a better performance of the control groups regarding the expression in the posttest. That may result in a similarly better performance in the expressions of measurement in the posttest. Sparing more upward space for them should therefore be suitable for establishing a comparable benchmark. All things considered, this way of clustering can yield a more promising result for the effectiveness experiment of the concordance-based material.

The material is given to the two experimental groups (FY1 and SY1) before they takes the posttest. (Note again that details concerning the number of research participants, gender distribution, and proficiency level can also be found in Kongsuwannakul (2009).) They all have fifteen minutes during class time to study individually and quietly over the one-page material. No further explanation is given to them during this study time. The material is then collected. They are not allowed to take it back as this may lead to the sharing of the material with the control groups. Within the very same week yet in the second class session, the experimental groups take the posttest.

It should be noted here that one underlying reason for using two groups of students for the control pair and another two groups for the experimental pair is the consolidation of the discovery. For one thing, in the pretesting step (see Section Empirical difficulty of the expression for Thai students), eliciting data from informants in two different sections could reduce the probability of encompassing a relatively stronger or weaker group by chance (cf. Section Empirical difficulty of the expression for Thai students). Secondly, having two different groups of informants for the experimental cluster and the control cluster each can also mitigate the effect of the testing time factor. For instance, some may argue that giving the material to the students in the morning exploits their fresh brain power. Thus, data can be naturally collected during their normal class time without much worry about differing testing time.

Moreover, in the posttesting step, having two groups for the experimental and control pairs each could also lessen the probability of being interdependent between the concordance material's effectiveness and the group/section variable. In other words, the effectiveness should probably be seen across the two different experimental groups if the material is truly effective. As a consequence, the findings from the implementation of this concordance-based material could be strongly substantiated. 
The four research sample groups take the posttest two weeks after their pretest. The twoweek interval is meant to create reliability in the control groups and less variance in the experimentation. With the same marking criterion as in the pretesting step, their performance data are obtained and then analyzed statistically, yielding the following results:

Table 1: The Mean Scores of the Four Sample Groups in the Posttest

\begin{tabular}{|l|c|c|c|c|c|}
\hline Group & Mean & Standard Deviation & N & Male & Female \\
\hline First Year 1 (FY1) & 18.9423 & 7.46604 & 52 & 17 & 35 \\
\hline First Year 2 (FY2) & 9.2368 & 8.00484 & 38 & 10 & 28 \\
\hline Second Year 1 (SY1) & 20.1471 & 6.16998 & 34 & 10 & 24 \\
\hline Second Year 2 (SY2) & 8.9375 & 6.81525 & 32 & 5 & 27 \\
\hline
\end{tabular}

From Table 1, it is clear that the experimental groups can really outperform their corresponding counterparts. To affirm this outcome and verify whether these average scores are really different from each other in a statistical way, an ANOVA (analysis of variance) of the posttest mean scores is conducted, and the following is its result:

Table 2: A One-way ANOVA Comparing the Posttest Means of the Four Sample Groups

\begin{tabular}{|l|c|c|c|c|c|}
\hline Source & df & SS & MS & $F$ ratio & Sig. * \\
\hline Between groups & 3 & 4140.184 & 1380.061 & 26.520 & .000 \\
\hline Within groups & 152 & 7909.835 & 52.038 & & \\
\hline Total & 155 & 12050.019 & & & \\
\hline
\end{tabular}

Table 2 shows $F=26.52,3 / 152 \mathrm{df}, p \leq$. 001. It indicates that with equal variances assumed, there is really a statistically significant difference between the sample groups of the study at 99.9 percent of reliability. To see which sample group's average score is statistically different from the other three, the use of a Scheffé test is also carried out upon the elicited data. The following are the results: 
Table 3: Multiple Comparisons of the Posttest Scores of the Four Sample Groups with the Scheffé's Test

\begin{tabular}{|c|c|c|c|c|c|c|c|}
\hline & \multirow{2}{*}{$\begin{array}{l}\text { (I) Sec- } \\
\text { tion }\end{array}$} & \multirow{2}{*}{$\begin{array}{l}\text { (J) Sec- } \\
\text { tion }\end{array}$} & \multirow{2}{*}{$\begin{array}{l}\text { Mean Differ- } \\
\text { ence }(I-J)\end{array}$} & \multirow{2}{*}{ Std. Error } & \multirow{2}{*}{ Sig. } & \multicolumn{2}{|c|}{ 99\% Confidence Interval } \\
\hline & & & & & & Lower Bound & Upper Bound \\
\hline \multirow[t]{12}{*}{ Scheffé } & SY1 & SY2 & 11.20956* & 1.77672 & .000 & 5.1220 & 17.2971 \\
\hline & & FY1 & 1.20475 & 1.59100 & .902 & -4.2464 & 6.6559 \\
\hline & & FY2 & $10.91022 *$ & 1.70293 & .000 & 5.0755 & 16.7449 \\
\hline & SY2 & SY1 & $-11.20956^{*}$ & 1.77672 & .000 & -17.2971 & -5.1220 \\
\hline & & FY1 & $-10.00481 *$ & 1.62078 & .000 & -15.5580 & -4.4516 \\
\hline & & FY2 & -.29934 & 1.73079 & .999 & -6.2295 & 5.6308 \\
\hline & FY1 & SY1 & -1.20475 & 1.59100 & .902 & -6.6559 & 4.2464 \\
\hline & & SY2 & 10.00481* & 1.62078 & .000 & 4.4516 & 15.5580 \\
\hline & & FY2 & $9.70547 *$ & 1.53954 & .000 & 4.4306 & 14.9803 \\
\hline & FY2 & SY1 & $-10.91022 *$ & 1.70293 & .000 & -16.7449 & -5.0755 \\
\hline & & SY2 & .29934 & 1.73079 & .999 & -5.6308 & 6.2295 \\
\hline & & FY1 & $-9.70547 *$ & 1.53954 & .000 & -14.9803 & -4.4306 \\
\hline
\end{tabular}

From Table 3, it can be seen from the asterisks that each experimental group has a mean score that is significantly different from any of the control groups. For example, in the first row, the mean score of the SY1 experimental group is statistically different from the mean scores of the SY2 control group and of the FY2 control group, too. It, however, does not differ significantly from that of the FY1 experimental group. So, the mean scores of the two experimental groups truly differ from those of the two control groups at the $99.9 \%$ confidence level. It can thus be claimed that the concordance-based self-study material could really raise their awareness of the construction under discussion and have the students learning it effectively.

\section{Concluding Remarks and Implications}

In this paper, experimentation with a concordance-based material has been reported. It is meant to respond to a structural problem for Thai students-constituent misordering in English expressions of measurement. In a preliminary study (Kongsuwannakul 2009), the importance of the expression has been underscored and empirically proved in the way that it could very plausibly be induced by negative transfer, in which a target language feature is different from that in an L1 and becomes a challenge to ESL students (see, e.g., Ellis 1994; Cortés 2006 for further information and examples).

The material is developed with a view to pointing out the distinct English ordering to the students. It is designed as a self-study material with Flowerdew's (2009) proposal of 'intervention' by hints and prompts taken into account (cf. Section Design of concordance-based self-study material). At the end of the concordance, five short guiding questions are provided so as to ensure that the students' awareness of the differing ordering of the expression existing in their mother tongue and English are duly raised.

In the pretesting step (see Section Expressions of Measurement in Previous Research) the control groups and experimental groups perform equally. Yet in the posttesting, the analysis of the elicited data confirms that the material is effective with high reliability $(99.9 \%)$. That is, 
the experimental groups, who are individually exposed to the material in the class session before the posttesting session, score far better than the control groups, who have not received any special treatment between the pretesting and posttesting. Plausibly, the concordance-based material facilitates purposeful learning for the former.

The aim of the material development is not to replace but complement other ELT approaches. As earlier argued, there is still room for concordance-based materials targeted at difficulty in structural/grammatical features. Construction of such materials for other similar structural problems instigated by negative transfer should likely yield positive results. They can somehow complement normal classroom settings, especially where large class size is a challenge.

Note that negative transfer should not go unresolved or neglected. For a long time, Odlin $(1989,23)$ has stated in his classic publication on language transfer that though there are a number of non-linguistic factors affecting second language acquisition such as motivation and class size, "there are reasons to believe that cross-linguistic influences [still] work in tandem with the psychological factors governing developmental sequences" [italics mine]. He insists that, in other words, from a large number of studies, differences in acquisition can anyway be ascribed to cross-linguistic influence (i.e., transfer) as one of the many factors for language acquistion.

In one way, the findings here suggest another promising way of self-study material production. In traditional terms, self-study material-be it for ESP or proficiency development-may encompass a variety of exercise forms such as matching, cloze-testing, reading and short answering etc. This current experiment, therefore, confirms that concordancing can be another effective exercise format for self-study material, especially when it comes to form-focused language points. If a paper-based concordance-based material like the present one works, then an electronic form, for example, should work likewise. A complete and self-contained self-study material will enable teachers to better manage their time and tackle only necessary points in class in a richer and more extensive manner. In addition, another implication is that concordancing could be applied to other form-focused points for class or outside-of-the-class material. DDL can be a potential helper for successful autonomous learning, thriving in large-class challenge (cf. Section Design of concordance-based self-study material). This, of course, will require further research for attested validity.

With regard to bottom-up and top-down processing, the material in the current experimentation apparently adopts a bottom-up approach. However, this is by no means to suggest that bottom-up application of concordance-based material would always be the case, since "whether the starting point should be with a bottom-up or top-down approach is not an easy question to answer and very much depends on the nature of the query and composition of the corpus" (Flowerdew 2009, 402). A safe argument here is therefore to encourage a variety of more form-focused applications of concordance-based material in various settings, so that a comprehensive body of insights could be achieved.

So far, concordancing, for one thing, has shown great potential for unveiling from 'multiword phenomena' through 'patterned preferences' (McCarthy and Carter 2002, 8-9). Apart from what I have mentioned above, I would recommend for further research a) the exploration of such an interlingual structural distinction, and b) the experimentation of concordance-based material on English learners of other native (L1) languages. To be specific, a variety of structural differences in a number of expressions or constructions can be issues for cross-linguistic research. A pair of languages can be explored in relation to a particular structure or expression. This can pave a way for more concordance-based research applications. If distinction exists, concordance-based material can be specifically designed to tackle such a challenge to the learners, and contributing factors for the implementation of this kind of material can also be investigated in detail.

As regards further applications, note that this experimentation exploits an indirect application of concordance-based material for the sake of research practicality (see also Section Design of 
concordance-based self-study material). I also find this indirect use, as discussed in the mentioned section, allows a wider accessibility at low costs for a lot of students-not to mention the availability of concordancers and students' concordance literacy. However, should a full direct use be investigated elsewhere, it would be interesting in my opinion to compare and contrast the effectiveness of direct and indirect use of concordance-based material.

\section{Acknowledgments}

Special thanks go to Asst. Prof. Phanintra Teeranont, Ph.D. for her proofreading of the first draft of this paper. Without her help, this paper must have been much more confusing. I also owe big thanks to Wireka Panchamanont, Ph.D. and Theeraphong Bualar, Ph.D. for their constructive comments on how to improve the recent draft of the paper. Without them, again, my paper would never come to its present form. However, any errors remaining in this paper are by all means my sole responsibility. 


\section{REFERENCES}

Aston, G. (2002). Getting one's teeth into a corpus. In Corpus Studies in Language Education, edited by Melinda Tan, 131-143. Bangkok: Institute for English Language Education Press.

Bartsch, S. (2006). History of Corpus Linguistics. ca. 2006. Retrieved October 2011 from http://www.linglit.tu-darmstadt.de/fileadmin/linglit/bartsch/ws06-07/corpuslinguistics/corpling-2-history.pdf.

Bax, S. (2003). The end of CLT: A context approach to language teaching. ELT Journal 57(3), 278-287.

Byrd, P. (2008). The difficult-easy matrix: Analyzing grammar from two points of view. Retrieved October 2011 from http://www2.gsu.edu/ eslhpb/grammar/difmatrx.htm.

Byrd, P., \& Coxhead A. (2010). On the other hand: Lexical bundles in academic writing and in the teaching of EAP. University of Sydney Papers in TESOL 5, 31-64.

Ching, L.P., \& Wong, I.F.H. (1994). Using concordance-based material for teaching verb inflections. TESL Reporter 27(2), 50-54.

Cortés, N.C. (2006). Negative language transfer when learning Spanish as a foreign language. Interlingüística 16,1-11. Retrieved September 2011 from http://dialnet.unirioja.es/servlet/fichero_articulo?codigo $=2514223 \&$ orden $=0$.

Ellis, R. (1994). The study of second language acquisition. Oxford: Oxford University Press.

Ellis, R. (2005). Principles of instructed language learning. Asian EFL Journal 7(3), 1-16.

Flowerdew, J. (1993). Concordancing in language learning. Perspectives 5(2), 87-101. Retrieved March 2011from http://sunzi1.lib.hku.hk/hkjo/view/10/1000064.pdf.

Flowerdew, L. (2009). Applying corpus linguistics through pedagogy: A critical evaluation. International Journal of Corpus Linguistics 14(3), 393-417.

Hasagawa, Y., Lee-Goldman, R., Ohara, K.H., Fujii, S., \& Fillmore, C.J. (2010). On expressing measurement and comparison in English and Japanese. In Contrastive Studies in Construction Grammar, edited by Hans C. Boas, 169-200. Amsterdam, The Netherlands: John Benjamins, in press.

Kanjanawasee, S. (2005). Classical test theory [in Thai]. $5^{\text {th }}$ edition. Bangkok: Chulalongkorn University Press.

Kilgarriff, A. (2009). Corpora in the classroom without scaring the students. Proceedings of the $18^{\text {th }}$ International Symposium on English Teaching, Taipei. Retrieved January 2011 from http://www.kilgarriff.co.uk/Publications/2009-K-ETA-Taiwan-scaring.doc.

Kongsuwannakul, K. (2009). Another evidence of cross-linguistic influence: A reflection through university students' performance on expressions of measurement. The International Journal of the Humanities 7(1), 293-308.

Laufer, B., \& Girsai, N. (2008). Form-focused instruction in second language vocabulary learning: A case for contrastive analysis and translation. Applied Linguistics 29(4): 694-716.

Longman Exams Dictionary. (2006). Essex, UK: Pearson Education.

McCarthy, M., \& Carter, R. (2006). This, that and the other: Multi-word clusters in spoken English as visible patterns of interaction. In Exploration in Corpus Linguistics, edited by Michael McCarthy, 7-26. Cambridge, UK: Cambridge University Press. Originally published in 2002.

Nation, P. (2003). The role of the first language in foreign language learning. Asian EFL Journal 5(2), 1-8.

Nunan, D. (2001). The second language curriculum in the new millennium. FIPLV World News [html], 51. Retrieved November 2011 from http://www.fiplv.org/News/fiplv news/news51.htm. 
Odlin, T. (1989). Language transfer: Cross-linguistic influence in language learning. Cambridge, UK: Cambridge University Press.

Poole, A. (2005). Focus on form instruction: Foundations, applications, and criticisms. The Reading Matrix 5(1), 47-56.

Schmidt, R.W. (1990). The role of consciousness in second language learning [abstract]. Applied Linguistics 11(2), 129-158. Retrieved August 2009 from http://applij.oxfordjournals.org/cgi/content/abstract/11/2/129.

Sripicharn, P. (2003). Evaluating classroom concordancing: The use of concordance-based materials by a group of Thai students. Thammasat Review 8, 203-236.

Supatranont, P. (2005). A comparison of the effects of the concordance-based and the conventional teaching methods on engineering students' English vocabulary learning. Ph.D. diss., Chulalongkorn University. Retrieved August 2010 from http://www.arts.chula. ac.th/ ling/thesis/Pisamai2548.pdf.

Tan, M. (2002). Corpus studies in language education. Bangkok: Institute for English Language Education Press.

Thailand, R.I. (1999). Guideline for Thai romanization [in Thai]. Retrieved January 2009 from http://www.arts.chula.ac.th/ ling/tts/ThaiRoman.pdf.

Thurstun, J., \& Candlin, C.N. (1998). Concordancing and the teaching of vocabulary of academic English. English for Specific Purposes 17(3), 267-280.

UNESCO. (2006). Practical tips for teaching large classes: A teacher's g uide. Bangkok: UNESCO Bangkok.

Zhang, S. (2008). The necessities, feasibilities and principles for EFL teachers to build a learneroriented mini-corpus for practical classroom uses. Asian EFL Journal-Professional Teaching Articles, 102-120.

\section{Appendix A. Sentences used in the test (Kongsuwannakul 2009, 307-8)}

1. Please dig a hole around 12 inches deep.

2. The Dead Sea is 420 meters below sea level.

3. The conference will be three days long.

4. The Grand Canyon is 4000 feet deep.

5 . The bus was ten minutes early.

6. The plant's leaves are 10 to $20 \mathrm{~mm}$ wide.

7. Christmas is only a month away.

8. The speech was twenty minutes long.

9. Geneva is about 20 miles away.

10. The waves were up to 40 meters high.

11. She was sitting ten feet away from the microphone.

12. That house is 50 meters above sea level.

13. The stream is three miles long.

14. I always keep my watch 15 minutes fast.

15 . The bridge is 140 feet long.

16 . This area is only two miles wide.

17. The road is five meters across.

18. Doi Suthep is located 3500 feet above sea level.

19. I was a few minutes early for my appointment.

20 . The beach is only five minutes away.

21 . The shop is five miles away from here.

22. In winter, temperatures dip to 40 degrees below freezing.

23. The river is more than fifty yards wide.

24 . The bus came ten minutes late. 


\section{Appendix B. Concordance-based Self-study Material on Expressions of Measurement}

Please study the texts in the box carefully and answer the following questions to yourself.

Doi Inthanon is located 8500 feet above sea level.

That house is 50 meters above sea level.

The street is four meters across.

He was sitting seven feet away from the microphone.

The river is $3 \mathrm{~km}$ away.

The lake is about 4 miles away.

Frankfurt is about 20 miles away.

The shop is five miles away from here.

The sandy beach is only ten minutes away.

Halloween is only a month away.

In winter, temperatures dip to 40 degrees below freezing.

The lake is 100 meters below sea level.

Bryce Canyon is 800 feet deep.

Dig a hole around 5 inches deep.

I was several minutes early for my appointment.

The car was twenty minutes early.

I always keep my watch 5 minutes fast.

The waves were up to 20 meters high.

The bus came twelve minutes late.

The conference will be five days long.

The bridge is 120 feet long.

The log was three meters long.

The stream is five miles long.

The speech was twenty minutes long.

The tree's leaves are 20 to $30 \mathrm{~mm}$ wide.

This area is only one mile wide.

The river is more than twenty yards wide.

1. What are all of these sentences about?

2. What are all of the words in bold type about?

3. What are all of the italicized phrases about?

4. Between the bold words and the italicized phrases, which come first and which come next?

5. If you translate these sentences into Thai, does the order of the words and phrases still remain the same, or does it change? 


\section{ABOUT THE AUTHOR}

Kunlaphak Kongsuwannakul: I graduated from Chulalongkorn University, majoring in Secondary Education (English and German) for my B.Ed. and in English for my M.A. My thesis is "Characteristic Features in English Acknowledgements Written by Thai Graduates: Indicators for Thai English," which is a study under the theory of world Englishes. Therefore, my interests lie in characteristics of new Englishes, English language and teaching, and applied corpus linguistics. I am currently a postgraduate research student at the University of Leicester, UK. Upon graduation, I will be legally obliged to return to Thailand and work as lecturer at the School of Foreign Languages, Institute of Social Technology, Suranaree University of Technology, Nakhon Ratchasima 30000, Thailand. 